\title{
Development Paths and Mechanisms of Green Collar Human Resource in China: Based on Classification and Green Literacy Survey
}

\author{
Liu Junzhen*, Ji Yunfei, Wang Hongxuan, Liu Yu \\ Department of Human Resource Management, Business School, Nankai University, Tianjin, China
}

Email address:

liujunzhen@nankai.edu.cn (Liu Junzhen)

${ }^{*}$ Corresponding author

\section{To cite this article:}

Liu Junzhen, Ji Yunfei, Wang Hongxuan, Liu Yu. Development Paths and Mechanisms of Green Collar Human Resource in China: Based on Classification and Green Literacy Survey. International Journal of Natural Resource Ecology and Management. Vol. 3, No. 5, 2018 , pp. 89-96. doi: 10.11648/j.ijnrem.20180305.12

Received: October 12, 2018; Accepted: November 1, 2018; Published: November 28, 2018

\begin{abstract}
With the development of concerns about environmental issues and advocacy and layout of the Green Economy in almost every country, a large number of Green-collar human resources demands inevitably have emerged. Green collar human resource development has become extremely urgent and important. It becomes significant to explore the approaches and major mechanisms for the development of green collar talent resources. Based on the clarification of the green meaning and extension meaning, and the literature review of green work, green employment and green collar, the authors summarize and analyze the unique working and living values, norms and behaviors of green collar. Then, 300 Chinese white-collars in workplace were investigated for their Green Literacy in their daily work and life. The survey found that the green behavior of employees in their daily work and life is not optimistic, and lacking of environmental legal knowledge, know-how skills of coping environment and pollution issues, supportive hardware facilities and cultural atmosphere were major Problem. According to the two essential classification dimensions of the Green-collars: green work and work greenly, the authors put forward the following categories of Green-collar human resources: "Non-green collar", "Light green collar", "Fake green collar", "True green collar" and "Decent green collar", Accordingly two typical evolution paths and development approaches were identified. Finally, the authors proposed and discussed the major Green-collar talents development mechanisms, including national green macroeconomic guidance, government policy support, green company certification and green management practices in enterprises, green culture propaganda, green-collar talents education and training, green collar work and life support in workplace, and society communication between green collars.
\end{abstract}

Keywords: Green Collar, Green Literacy, Green Collar Classification, Human Resource Development, Development Paths and Mechanisms

\section{Introduction}

The development of a green economy is an inevitable choice for countries all over the world to overcome economic and social development difficulties and achieve sustainable growth, especially for China, which is under the pressure of rapid economic development and constant environmental protection and environmental crisis. The green economy will definitely change the economic structure and development model and promote profound changes in social development. With the government's efforts to promote industrial upgrading and transformation, energy conservation and emission reduction, shutting down zombie enterprises, promoting supply-side reform, investing in green and clean energy technologies, fostering environmentally friendly enterprises, and promoting green development of enterprises and green transformation of the economy, all above these efforts will be important forces on the green collar human resources demands, and promote the growth of the social green collar talents. Green collar human resources are closely related to green employment and green jobs. According to the definition of the International Labor Organization and the United Nations 
Environment Program (2007), green employment refers to decent work created in the economic sector and economic activities that mitigates environmental impacts and ultimately achieves environmental, economic and social sustainability.

From the perspective of the world's major countries, the United States now has 750,000 "green collar" jobs. By 2030, at least 21 million new jobs will be created in the renewable energy industry, with about $25 \%$ green-collars in the United States workforce. In 2000, the number of direct employment in the eco-industry in the EU had reached 2.4 million. In the broad sense, the number of direct employment in environmental-related industries reached 20.9 million, accounting for about $10 \%$ of the total employment in the EU [1]. Since 2006, by expanding into the renewable energy sector, Germany has created 235,000 green jobs, including wind, solar and biofuels, and it is estimated that green jobs will reach 500,000 in 2020 [2]. Singapore is vigorously developing green building projects with the goal of achieving $80 \%$ green building by 2030 and 20,000 green talents by 2020 .

In general, Green-collar work, green employment will become a new type of work and employment in future society. Low-carbon industry investment and green collar development will be a win-win strategy for the economy, employment, environment and social development. How to effectively develop a large number of green-collar talents to support the transformation and development of Chinese Green Economy is the challenge that should face sooner or later. Especially, on the basis of excavating the nature of Green-collar talent and its classification, identifying the growth path of green-collar, exploring the approaches and choices of Green-collar human resource development, establishing the key mechanism of green-collar talent development will play an important guiding role and make huge contribution to the development of Chinese economy transformation and its human resource development.

\section{Literature Review}

\subsection{Green}

Green, which is a mixture of blue and yellow, is often seen as a harmonious color, symbolizing calm and tranquility, friendliness, nature, life and hope, balance, harmony and peace. Medically, moderate green can relieve eye fatigue, eliminate nervous tension, and improve heart function. Green is also effective in treating diseases such as nervous system diseases, fever, ulcers, flu, malaria, sexually transmitted diseases and cancer. Green means "safety", "convenience and environmental protection", and green also means "no pollution, clean", "high efficiency", "advancement", "scientific" and "recyclable". Green refers to ecology and environment. Under the guidance of scientific theory, all the feature of activities that humans adapt to the environment, develop in harmony with the environment, and progress in harmony can be addressed "green".

\subsection{Green Work and Green Employment}

According to the Bureau of Labor Statistics of the US Department of Labor, Green work was defined as: The products produced or services provided are beneficial to the protection of the environment or natural resources, or make the production process more environmentally friendly or use less natural resources [3]. The Labor Science Research Group of the Ministry of Human Resources and Social Security of China defines green work as: Work in the process of economic greening, engaged in green economic activities, and work in relevant green industries, departments, enterprises and positions. In general, green jobs add environmental values (such as environmental friendliness, energy conservation, etc.), social values (such as decent work, work contributions, etc.) and individual values (such as personal values) compared to traditional work that only reflects economic value. For employment statistical considerations, the US Bureau of Labor Statistics divides green employment into two categories: firstly, employment in green products and services, and secondly, employment in green technology and practice. The first category refers to the products produced and the services provided are beneficial to the environment or to the protection of natural resources, including research and development products or services, installation and maintenance. The second category refers to the use of green products, green services, environmentally friendly methods, processes or technologies.

Feng Ling (2013) proposed four kinds of green employment [4]: the first is direct green employment that has a direct positive impact on the improvement of ecological environment quality, such as afforestation, sanitation, wildlife conservation work. The second is indirect green employment, which refers to environmental protection related laws, policies, scientific research, finance, management, trade, education and consulting. The third is greening employment, that is, by optimizing production technology and products for greening employment of non-green industries, thereby achieving energy conservation and emission reduction purposes, such as new steelmaking technology and recycling, organic agriculture, green textiles, and new energy. The fourth is pan-green employment refers to employment in industries that have less negative impact on the environment, including employment in many tertiary industries, such as education and training, information industry, and cultural industries.

\subsection{Green Collar}

\subsubsection{The Concept and Connotation of Green Collar}

Patrick Heffernan first mentioned Green Collar in his report to the US Congress. The United Nations Environment Program defines green collar as workers in agriculture, manufacturing, research and development, management and service activities, whose work can play an important role in maintaining and restoring environmental quality, such as helping to conserve ecosystems and biodiversity, helping reduction of energy consumption, reducing economic carbon intensity, reducing or completely avoiding all forms of waste and pollution emissions. 
According to Webster's Dictionary, Green Collar was defined as engaged in environmental sanitation, environmental protection, agricultural research, forest protection and greening, as well as those who like to use the outdoors and the mountains as their dreams. Thus, green collar definition by it has exceeded the scope of green employment; it refers to a kind of life interest: Green collar is not specific to a certain group in society, but a life attitude and behaviors.

The Future Green Youth Leaders Association defines green collars as: A group of all global citizens who consciously abide by the laws of nature and whose ideas and behaviors are consistent with the concept of sustainable development. In the book "Green Collar Economy", Jones, a special adviser to the White House Green Work, pointed out that the green collar is to promote the environmental concern firstly, and to work in the environmentally friendly field secondly. This paper argues that green collar refers to those who contribute to the improvement of the ecological environment, in the green industry, in green jobs, and in those who work and live greenly, that means yearning for, advocating a more healthy, natural, environment-friendly, simple and sustainable lifestyles, and supporting for public welfare. In general, the green collar includes green-collar workers in the enterprise, green-collar members in the family, and green-collar citizens in the society. They work in green jobs or in green industry sectors or they work greenly in their working field.

\subsubsection{Green-collar Generation and Its Working and Living Values}

The emergence and development of green collar are rooted in resource destruction and environmental pollution that are deteriorating in people and society, people and the environment. The malignant mining of energy, the reduction of total energy supply, the rise of energy and price, the acceleration of social rhythm, the excessive pressure of work and survival, the fatigue of employees, lack of happiness, and the desire to return to a healthy life. The emergence and development of the green collar is a manifestation of the modern life of urban youth fleeing tension, and it is the collective reflection of people's urban life. Green collar usually has relatively unique and progressive working and living values and pursuits, such as: loving the environment and life, low carbon, natural simplicity, advocating health and happiness, obeying social rules, respecting tolerance and so on Green collar usually has unique working and living habits, including:

(1) Save and control energy consumption, such as proper house decoration; using natural materials; using natural lighting and natural wind in the office during the day; not adjusting the air conditioning temperature to below 26 degrees.

(2) Save on the use or reuse of office supplies and consumables, such as using recycled paper as much as possible; reducing the use of paper cups and disposable chopsticks; reading electronically and not through printed paper if necessary; double-sided and small printing a document.
(3) Maintain the machine and computer regularly, such as dustproof and moisture proof work, in order to operate them efficiently and save electricity.

(4) Take fewer elevators and more stairs; walk to work or use public transportation; use video conferences and arrange less business trips.

(5) The office and the home are neat and tidy, and there are not too many sundries; the items are sorted and classified; the garbage is taken out at the door regularly and not polluted to the environment.

(6) Rational consumption, reasonable planning, no over-consumption; no waste of food and other resources; shopping without plastic bags; changing consumption patterns from "Mianzi" concerns to more rational and healthy.

(7) Use organic food, natural materials; eat more vegetables and less meat; do not eat wild animals; turn off the mobile phone once coming back home; not be bothered by too much electronic information.

(8) Love outdoor sports, such as aerobics, climbing-mountain, making body more healthy.

(9) Participate in and support the global environmental protection actions and social welfare actions, such as the Earth for one hour, cleaning up garbage, and protecting animals.

\subsubsection{Summary of Green Collar Research}

The concept of green collar is relatively late and there are few related studies. To sum up, it is generally believed that people with "green collar" work and life habits have a healthier and more active attitude and work more efficiently. They are more popular with colleagues in the workplace and work more smoothly. Green collar work is more occupational safety and decent [5]. Meanwhile, the green-collar work is conducive to the faster increase of compensation. For example, the average salary of green-collar workers in Europe and the United States is $10 \%-20 \%$ higher than the average salary of other industries [6]. As the green collar and their work can directly lead to the improvement of productivity and enterprise efficiency, many enterprises are increasingly inclined to "green collar", because they are paying attention to public welfare, investing in environmental protection, caring and responsible, knowing to protect the ecology, saving corporate resources and paying attention to the sustainable development of the company. As a result, the person who become a green collar is also the most likely to succeed.

\section{Survey Findings on Green Literacy of Chinese White Collar}

\subsection{Purpose and Sample Description}

In order to understand the green literacy level of Chinese white collar in workplace, we surveyed 300 respondents. They are mainly from the sector of manufacturing (20\%), service $(22 \%)$ and finance $(16 \%)$. The scale of the company that sample employee work in varies greatly, the scale of employee 
ranges from less than 100 to more than 3,000. The respondents mainly come from State-Owned Enterprises (46\%) and private enterprises in China $(36 \%)$. They are mostly in management positions $(70 \%)$, and the percentage of senior level, middle level and grassroots personnel is: $16 \%, 42 \%$, $42 \%$. The sample employees almost get Bachelor's degree at university $(49 \%)$ or degree of Postgraduate, MBA or $\mathrm{PhD}$ (47\%). Their work locations distribute in the main big cities in China: Beijing (17\%), Shanghai (6\%), Tianjin (39\%), Shenzhen (5\%), Guangzhou (2\%), Chongqing (2\%), and other major cities $(29 \%)$.

\subsection{Survey Findings}

\subsubsection{People Generally Have a Strong Concern on Environment Issues, But They Lack Relevant Knowledge}

More than $70 \%$ of the respondents expressed concern about various environmental issues and environmental crises in the workplace and society, but only about $40 \%$ understand the relevant environmental laws and regulations, and $30 \%$ understand the knowledge of green products and green management certification.

\subsubsection{Lack of Green Skills Has Become Bottleneck That Restricts Green Literacy}

Nearly $80 \%$ of respondents want to integrate green technology, green management with their own work, and promise to provide customers with valuable products and services, and not to produce and deliver products that are harmful to the environment. However, up to $65 \%$ of respondents do not have the basic skills to solve the business pollution issues at work, and control energy consumption, waste issues and resource recovery. According to the SUSP survey data of Sichuan University, more than $50 \%$ of survey respondents do not know how to classify garbage, and less than $16 \%$ of survey respondents regularly classify garbage properly.

\subsubsection{People's Daily Green Behavior Is Not Optimistic, Supportive Hardware Facilities and Software Environment Have Not Yet Formed}

Nearly $50 \%$ of the respondents used Disposable paper cups and chopsticks, and more than $40 \%$ of them used plastic bags instead of green bags or their own shopping bags. One-third of the respondents did not chose to walk, ride or take public transport to work or short-distance travel, nearly $40 \%$ of the respondents choose to take the elevator instead of walking as far as possible if they face the lower floor. In addition, more than $70 \%$ of respondents claimed that they would suggest green and low-carbon work lifestyles to others if they had the opportunity, but less than $30 \%$ would hold back others' non-green behaviors. At the same time, when they discovered product development and production that are harmful to the environment, nearly $50 \%$ of the respondents will not make any suggestions or choose to protest or quit from company, they would like choosing silence.

\section{The Path and Mechanism of Green Collar Human Resource Development}

\subsection{Green Collar Classification and Development Path}

According to whether it works in the green industry sector or green jobs, and whether daily work behaviors meet the green standards, labor resources can be divided into four categories: (1) Non-green collar: they are not actively contributing to the environment and sustainable development. Working in the economic sector or in the post, the daily work behavior is also not green and low carbon. (2)Fake green collar: They work in green industry departments or green jobs such as environmental protection and new energy industry, but their work values, behaviors, and lifestyles still fall short of green standards. (3)Light green collar: Although these people do not directly engage in work that contributes to the environment, their work values and work behaviors have already met the green and low carbon standards. They contribute the environment indirectly and small through their daily work and life. (4)True Green Collar: These people work in the green industry sector that contributes the environment directly, and they also agree with the values of green work and life. The daily work and life behavior also meets the green standards.

If other positive elements are added to the above classification of "green collar", such as more safer work, more higher income than average compensation, more work security and more social recognition and higher social status, it can reach to the higher form of green collar-the fifth category -Decent green collar.

Based on these, it can be seen that the ultimate goal of green collar human resource development is to: cultivate "True green collar" and "Decent green collar" that meet the requirements of sustainable economic and social development within a certain time and space. The "Fake green collar" and "Light green collar" are the development process or stage to achieve this ultimate goal. The path of green collar human resource development can be divided into two (Figure 1).

The two lines represent two development paths: First path means the transformation from traditional industries or jobs to green industries or green jobs, and then to the "True green collar" that represents both internal green and external green, and finally to the "Decent green collar". The second path is not changing the type of industry or work, but increasing the green elements intrinsically, and achieving the transition from "Non-green collar" to "Light green collar", and then finding opportunities to contribute environmental performance directly and become "True green collar" and "Decent green collar" ultimately. 


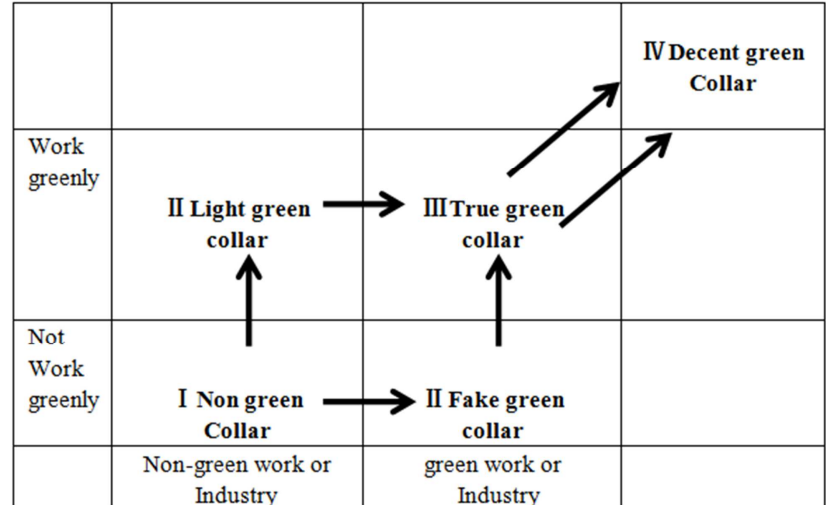

Figure 1. Green collar human resources classification and development path map.

In brief, the first path means industry change, job change from traditional to more green. The second path means the change of more green values, more green knowledge, and more green behavior in one's work and life.

\subsection{Green Collar Human Resources Development Mechanism}

\subsubsection{Macro-leading and Government Policy Support for Green Economy: Creating More Green-Collar Employment Opportunities}

Firstly, we must adjust the industrial structure and develop a green economy. The Chinese government has set a target of $40 \%-45 \%$ reduction in $\mathrm{CO} 2$ emissions by 2020 compared with 2005, and introduced a series of policies on energy conservation and emission reduction and elimination of backward production capacity, thus setting the stage of industrial restructuring for green economy development. The transformation and upgrading of the green industry is to guide the production factors to the modern service industry, advanced manufacturing industry, strategic emerging industries, and traditional advantageous industries. Adjusting the current misallocation of large amounts of capital to material property, fossil energy, structured financial assets and derivatives, investing more in green buildings (such as energy-efficient buildings, new materials, new standards, etc.), renewable energy and clean energy (such as wind, solar, bioenergy, hydropower, geothermal, etc.), green and smart transportation, freshwater resources, ecological infrastructure, sustainable agriculture, smart grids, and areas such as waste recycling. Increase the support for energy-saving and emission-reducing industries, technologies, products and related enterprises. At the same time, adopt high-tech transformation to enhance the advantages of traditional industries, take the green development path of independent innovation, cleaner production and circular economy, and then expand the green collar and job opportunity.

Secondly, provide support and guidance for green entrepreneurship and green enterprises in order to let people know once they start a business or seek a job, it must be green first.

Thirdly, increase the research and development efforts and application of green technologies, such as energy-saving and emission reduction technologies, environmental protection technologies, low-carbon technologies, clean energy and clean production technologies, recycling technologies, new materials technologies, green consumer technologies, biotechnology, etc.

Fourthly, effectively promote the development and upgrading of the regional green economy through the construction of green industrial clusters and green eco-industrial zones.

Fifthly, set up special fiscal investment and subsidies to support the green economy and green employment. Governments should do research on the mechanisms and policies for green-collar economy and green-collar talent development, and formulate relevant policies, plans and strategies, for example, research on policy support, research of green employment development strategy. They should pay attention to unemployment and other problems brought about by green economy transformation, strengthen labors' skills through training, encourage green entrepreneurship, establish special financial subsidies, such as low-interest loans, tax allowance and exemption, set rewards and provide green employment services to promote the development of green economy.

\subsubsection{Leading Mechanism for Green Enterprises and Green Management}

Firstly, expand the living space of green companies and promote the rapid development of China's green consumer market. Through the research and development, production and marketing of corporate green products, more green jobs will be increased and provided. By implementation of green management, green strategy, green culture, green office, more green-collar demands produced. For example, Green Company Strategy in Vanstone Real Estate Emphases on the core values of environmental protection, conservation, harmony and rational development, emphasizing the full range of employees, shareholders, customers, partners and society Green behaviors have established green building standards for safety, comfort, energy efficiency and consumption reduction.

Secondly, entrepreneurs must promote the awareness of green industries and actively adjust production mode by application of environmental protection technology, create more green jobs. At the same time, they should strengthen the qualification certification of green management and green jobs.

\subsubsection{Strengthen the Promotion of Green Work, Green Living and Green Consumption, and Guide the Formation of Green Collar Culture}

First of all, through the publicity reports such as green work typical cases or characters just like corporate executives, star's green action etc., advocate the philosophy of green work, green life, green consumption, leading the direction of public opinion and green cultural values. There are many examples of corporate executives who practice green in their daily work and life. They use their spare time and holidays to focus on 
environmental protection and participate in it.

Secondly, through the social demonstration of corporate green products, green technology and its green management practices, the green social atmosphere is gradually created.

\subsubsection{Improve the Education and Training Mechanism of Green Collar Human Resources}

First of all, every talent people must establish a green concept, they should master green knowledge, and improve the self-development awareness of green collar skills. Green collar skills and green literacy are basic competency that talents must have after information skills and information literacy in recent years. Understanding and investing in green jobs has become a compulsory course for everyone. It is generally believed that the transformation of blue-collar and white-collar workers into green collars requires two capabilities: cross-disciplinary knowledge and environmental values. Therefore, they need to:

(1) enrich environmental knowledge and understand relevant environmental legislation;

(2) understand green economy, green work, green and clean energy, green buildings, green materials, energy saving appliances and lighting equipment, hybrid power Automobiles, electric vehicles, water conservation, soil protection, organic natural production methods, and strive to deepen understanding of environmental protection equipment, technology, tools, products, materials, etc., improve the utilization of resources in work and life;

(3) understand the international standards and norms of green or low-carbon economy;

(4) change the philosophy of "first pollution, then governance", "only focus on growth and financial benefits, not care environmental protection", and establish ecological and sustainable values to enhance environmental literacy.

Secondly, national and regional green employment and training plans should be formulated in order to develop green-collar talents. Government should conduct research on demand and supply of green collar and its skills, and develop green-collar talent development plans in key industries, such as strategic emerging green industries, key ecological functional areas, and severe environmental problems industries. On this basis, green collar skills training and green entrepreneurship training should be developed and implemented. At the same time, the professional green qualification standard or certification system of green enterprise, green management and green collar must be established.

Thirdly, through the education and training efforts by colleges, vocational colleges, social training institutions and $\mathrm{NGO}$, a multi-layered green collar education and training structure is formed. By setting up green majors, green disciplines or adding green-related courses, universities and vocational colleges are constantly experimenting with ways and means of educating and cultivating green-collar talents to their college students. For example, a master's degree in sustainable architectural design is set up in Singapore's universities. The University of Nottingham is responsible for teaching and awarding diplomas to train advanced green technology talents. More and more business schools such as Stanford University, Oxford University, London School of Economics and Political Science, etc. are also offering courses such as "sustainable management" to train business professionals in specialized green industries. The Rennes Community College of the United States provides energy conservation and related vocational training and certification to individuals. The course focuses on understanding the energy system in integrating, analyzing and determining the energy-saving effects of residential and commercial buildings increase continually. [7].

\subsubsection{Support and Guarantee Mechanism for Green Collar Work and Life}

First of all, it is necessary to invest on and support green facility protection, such as setting up waste separation and recycling bins in communities, office places, streets, etc., using natural lighting design for office building construction and renovation, and installing energy-saving devices such as air-conditioning temperature sensing controllers. Add automatic duplex printing equipment, etc.

Secondly, strengthen relevant policy guarantees, such as hot water supply in a period of time, unified lighting policy, employee environmental protection commitment. The IT department of company can monitor the energy consumption of each person and each unit, and recognize their green environmental behavior.

Finally, provide relevant training delivery of green knowledge and skills, such as organizing employees to watch environmental videos, soliciting suggestions for employees' environmental protection and efficiency, and organizing environmental lectures.

\subsubsection{Establish Communication and Attribution Mechanism for Green Collars}

First of all, the green collar should actively advocate and respond to global, regional, and industrial green initiatives, such as the "Earth Hour" light-off event advocated by the World Natural Resources Foundation, and the Asian Cities Light-off Day to support climate change actions. Similar initiatives include: Environmental protection, energy conservation and emission reduction, green office, recycling of used batteries, community/campus ecological civilization, biodiversity conservation, beautification of living environment, action of Chinese beautiful countryside construction.

Secondly, through Green Collar club, green collar can gather and communicate each other, the feeling of collective and belonging produces.

Finally, government organizations or non-profit organizations should carry out and improve research on green economy, green management, green communities, green consumption, etc., and promote design competitions related to green technologies and green products, so that the green collar can continuously demonstrate its capabilities through the above platforms. 


\section{Conclusions}

Through our efforts, the following consensuses are reached:

(1) In Chinese workplace, the employees green literacy in their daily work and life is not optimistic, major Problem is lacking of environmental legal knowledge, short of "know-how" about coping environment and pollution issues, supportive hardware facilities not enough, and culture Green work and life not yet formed.

(2) According to essential meaning of green and Green-collar, the two essential classification dimensions were identified: green work(or industry) and work greenly(or work in green style), thus, the categories of Green-collar human resources are formed: "Non-green collar", "Light green collar", "Fake green collar", "True green collar" and "Decent green collar".

(3) Accordingly the above category, two typical evolution paths and development approaches were identified. Therefore, the major Green-collar talents development mechanisms, including macroeconomic guidance and government policy support, green company certification and green management strategy, green-collar talents education and training, and social supportive system will become the key way to develop green collar talents for o country or region.

At the same time, the cultivation and development of green-collar talents requires the government, industry, enterprises, social welfare organizations, communities, education and training institutions, employees and their families to reach consensus and form a joint force. It requires green government including green governance philosophy, green administrative standard, green structure, green policy, and green law enforcement. It requires employers to bear the social responsibility of green development in addition to economic benefits, vigorously develop green products and technologies, promote the adoption of green technologies, strengthen green management, and provide more green jobs. It requires advocating green consumption, green living style forming the green culture and atmosphere in the whole community.

\section{References}

[1] Berman E, T M Bui. Environmental Regulation and Productivity: Evidence from Oil Refineries[J]. Review of Economics and Statistics, 2001,(3).

[2] Bureau of Labor Statistic. Monthly labor review, 2013(5).

[3] Cory Hallam, Carolina Contreras. Integrating lean and green management. Management Decision, Volume: 54 Issue: 9, (2016).

[4] Douglas W S. Renwick, Tom Redman and Stuart Maguire. Green Human Resource Management: A Review and Research Agenda International Journal of Management Reviews, Vol. I5, $1-14(2013)$

[5] Fengying. Ji Hengkuan. Green New governance and Green Employment. The Impact of Science on Society, 2010(2): 10-13.
[6] Feng Ling. Research on the Construction of American Green Employment and Legal System. First Resource, 2013(1): 118126.

[7] Gao Hong. Green collar class is in the ascendant. Modern Corporate Culture, 2009(19): 46.

[8] Green Employment Development Strategy Research Group. Research on Green Employment Development Strategy. China Labor and Social Security Publishing House, 2013.

[9] Guoda. Xu Yanli. Green Vocational Education Creates Beautiful Tianjin. Tianjin Academic Library, 2014: 1285-1292.

[10] Helen Song-Turner, Michael Polonsky. Enviropreneurial marketing in greening corporate activities[J]. European Business Review, 28(5).(2016).

[11] Hiba A. Masri, Ayham A. M. Jaaron. Assessing green human resources management practices in Palestinian manufacturing context: An empirical study. Journal of Cleaner Production,(2016).

[12] Julie Rayner, Damian Morgan. An empirical study of 'green' workplace behaviors: ability, motivation and opportunity. Asia Pacific Journal of Human Resources Volume 56, Issue 1(2017).

[13] Lan Qingxin. Hanjing. Research on China's Industrial Green Transformation Strategy. Economic Reform, 2012(1): 24-28.

[14] Lanoie P, Partrym, Lajeunesse. Environmental regulation and productivity: new findings on the Porter analysis[R]. Cirano Working Papers, 2001.

[15] Licheng. Pengyu. China Green Occupation Classification and Comparison with the United States. Jiangxi Social Sciences, 2015(10): $211-216$.

[16] Liu Junzhen, Zhang Yajun, Liu Shiyue. Enterprise Green Human Resource management: System framework and Strategy generation. China's human resources development, 2014 (10): 26-31.

[17] Liu Junzhen, Fu min, Zhang Qing. New management Order: Welcome the rise of purple collar stratum. Tsinghua Management Review, 2017 (11): 66-73.

[18] Liujunzhen, Liushiyue. Construction of Trinity of talents cognitive based on the essence of spirits. Journal of Executive Leadership Academy Dabieshan, 2017 (11): 94-96.

[19] Liu Junzhen. How human resource management evolves in the VUCA Times. Tsinghua Management Review, 2015 (10): 36-42.

[20] Marta Ormazabal, Jose M. Sarriegi, Elisabeth Viles. Environmental management maturity model for industrial companies. Management of Environmental Quality: An International Journal, Volume: 28 Issue: 5, (2017).

[21] Mohd-Yusoff Yusliza, Nur Zahiyah Othman, Charbel Jose Chiappetta Jabbour. Deciphering the implementation of green human resource management in an emerging economy. Journal of Management Development, Volume: 36 Issue: 10, (2017).

[22] Pavitra Mishra. Green human resource management: A framework for sustainable organizational development in an emerging economy. International Journal of Organizational Analysis, Volume: 25 Issue: 5, (2017).

[23] Paillé P, Chen Y, Boiral O. The impact of human resource management on environmental performance: An employee level study, Journal of Business Ethics, 2014, 121(3): 451-466. 
[24] Petr Scholz, Jan Voracek. Organizational culture and green management: innovative way ahead in hotel industry. Measuring Business Excellence, Volume: 20 Issue: 1, (2016).

[25] Shoeb Ahmad. Green Human Resource Management: Policies and practices. Cogent Business \& Management, 2015:2(1).

[26] Shwu-Ing Wu , Yu-Chen Wu. The influence of enterprisers' green management awareness on green management strategy and organizational performance. International Journal of Quality \& Reliability Management, Volume: 31 Issue: 4, (2014).

[27] Stefano Garzella , Raffaele Fiorentino. An integrated framework to support the process of green management adoption. Business Process Management Journal, Volume: 20 Issue: 1, (2014).

[28] Warne Schneider. The union plan of working and environment in Germany. Green Work Experience Exchange Seminar in Beijing China, 2009.

[29] Yangyan. Research on the Guarantee Mechanism of "Green Collar" Talents Training in Higher Vocational Colleges. Vocational Education Research, 2014(3): 9-12.

[30] Zhang Lili. Thinking of training about green economic and managerial talents. Times and Finance, 2013(4): 71-75.

[31] Zhang Libin. Development of green employment. China Development and Observation, 2010(2): 41-46. 